\title{
From understanding of national design characters and suggestion of the improvement of Vietnamese urban outdoor furniture toward a sustainable cultural environment
}

\author{
Thi Thu Trang $\mathrm{Ngo}^{1, *}$ \\ ${ }^{1}$ University of Architecture Ho Chi Minh City, 196 Pasteurstr., dist. 3, Ho Chi Minh City, Vietnam
}

\begin{abstract}
Recognizing the threat of losing local identity under the pressures of modernization and globalization, the aim of the research is to extract the vital characteristics representing for a national style in order to propose a guideline for the modern industrial products in Vietnam in general, and urban outdoor furniture in particular. From the database of over two thousands Vietnamese traditional daily products, this paper presents the major results of analyses carried out on the use of materials, shapes and forms, colors and decoration, the four basic components of aesthetic appearance. The correlations between those four components are also looked at in this study. Continuously, all important results which show strength and distinction of each appearance's component are extracted and classified into clusters which recognize the repeat pattern of the overall characteristics of the four main appearance's components. The name of each cluster is listed as keywords of Vietnamese national identity such as Harmonious, Focused, Orthodox, Dynamic, Feminine, Slightly recessive, and Outward. Finally, the article suggests a sustainable solution for creating aesthetic identity of urban outdoor furniture by integrating those essential characters of tradition into the modern design. In other words, the characters of Vietnamese traditional daily products found out in this study are proposed as the guidelines for aesthetic improvement of Vietnamese urban outdoor furniture which can be an effective medium to introduce the culture of the local area and represents the image of a city.
\end{abstract}

\section{Introduction}

The pressures of modernization and globalization have brought about two threats in all fields of design: leaving behind traditional characteristics and merging national identities into one world. Traditional characteristics are the specific attributes, of a particular country, gathered over thousands of years, formed through the whole historical development of a country. These characteristics are unique and can never be replicated in their entirety, in any other country of the world. Naturally, they are part of that particular country's national

\footnotetext{
* Corresponding author: rang.ngothithu@uah.edu.vn
} 
identity. Therefore, preserving traditional characteristics is an effective way of keeping a national identity, as it flows from the past to the future.

Since the twentieth century, in the design field, efforts to restore and apply traditional values in contemporary designs have blossomed, for example in architecture, fashion and also in retrospection of product design. However, to integrate traditional characteristics into contemporary designs properly, the challenges are not only that the requirements of industrial mass-production do not complement the sophisticated details created by traditional craftspeople, but also that traditional patterns and the modern shapes and materials do not always in a good match. Therefore, if we integrate traditional characteristics into contemporary designs by simply picking up a traditional pattern or shape and putting it in a modern object or space, it would have limited success. A better solution is to extract the general characters from concrete traditional details, and then apply it to contemporary objects using modern elements. In this way, we can keep the traditional spirit alive in modern objects without facing the problems of conflict in appearance, especially in nowadays public space where the objects has to serve not only useful function for a mass, but decorative function for the modern urban environment as well.

\section{Literature review}

In the field of research, studies toward traditional craft's preservation and development have been carried out. Among over thirty articles found concerning this issue, the majority are on searching a way innovatively develop further or to extend the existence of traditional handicrafts, sometimes in the form of cultural heritage or as a living museum $[1,2]$. Some people have attempted to insert modern designs into traditional materials and techniques to increase the appeal for contemporary customers [3-7]. There are some designers that have tried to find a way to integrate the characteristics from traditional crafts into modern designs, yet those are limited and still personal. With the same idea, talking about sustainable city of the future, Jeffrey (2012) has stated "Modernism sought a universal, global style, the international style, replicable in any location around the word. But if a sense of ownership is central to sustainability, then style will likely remain fiercely local. Overly rigid local style enforcement can result in dull uniformity and kitsch, but the development of a particular local character can help make residents loyal to a particular place and eager to make social investments there"[8]. The role of street furniture has been emphasized in developed countries for a while, but not been paid attention in developing countries. There are limited number of comprehensive studies on street furniture are found in research field, only some design guidelines. In recent years, various street furniture guideline of cities (in Australia [9], Canada [10], etc.) and studies (e.g. Wan [11], Yu [12]) have mentioned about identity and aesthetic in street furniture design. It is even talked about creating "a singular aesthetic that can be easily recognizable and become the common elements weaving and linking the various communities of the city together including heritage and special character areas" [13]. However, the suggestions or guidance on direction of designing city's identity aesthetic have been neglected.

\section{Materials and methods}

With the aim of finding out the "guidepost" to the future object designs by integration of tradition, the research is carried out in order to exploring the characteristics and tendency of the use of material, form, color and decoration, the basic apparent components intraditional daily products (TDPs), and the correlation among those four components. TDPs are products which appeared before modern time. In this research, the samples are products found from 
prehistory until the Nguyen period ( $\sim 19$ th century). The samples were collected from museum visiting, published documents, and from the internet. Collecting form is a photo with detailed information of the product's function, production time, medium, dimension, color and decoration. The original amount of samples is 2164 products.

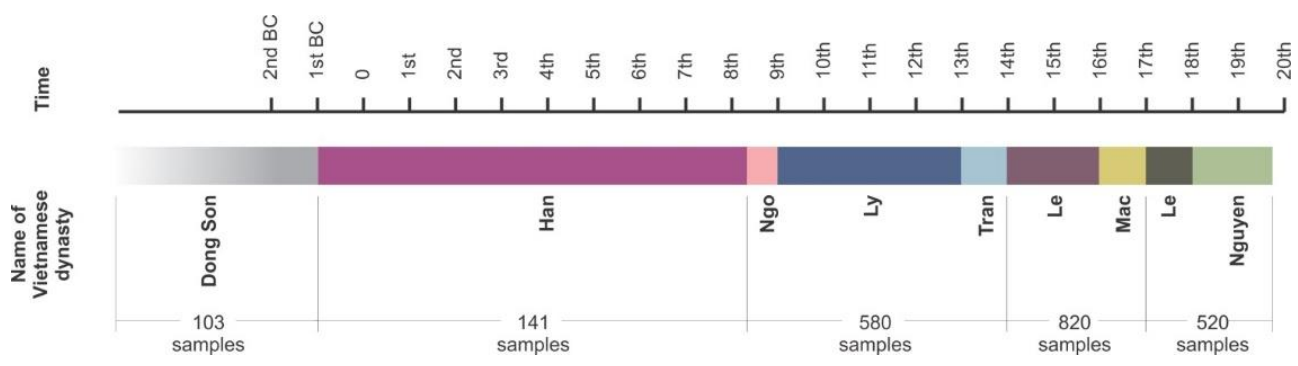

Fig. 1. The number of samples of each period of time.

Corresponding to the goal of the investigations and the type of data, the methods used for analyzing data of this research are as follows:

- Quantification Theory Type III Analysis: used for identifying the specification in utility of the apparent elements.

- Cluster Analysis: used for highlighting the relationship between the characteristics of each apparent element.

- Correspondence Analysis: used to understand the relationship between the apparent elements.

\section{Results}

It is generally understood that material, form, color and decoration are regarded as four basic components of a product's appearances. In this study, all those components have in turn been addressed. Following are the most significant results of each part of the research.

\subsection{The use of materials}

Among all results of investigation on the use of materials in Vietnamese TDPs [14], the graphs below (Fig. 2) present the difference in using materials in the various groups of products according to what they were used for: eating, drinking and living. It is obvious that wood, lacquer, ceramic, metal and bamboo are the most frequent used material for living ware of Vietnamese people in the past.

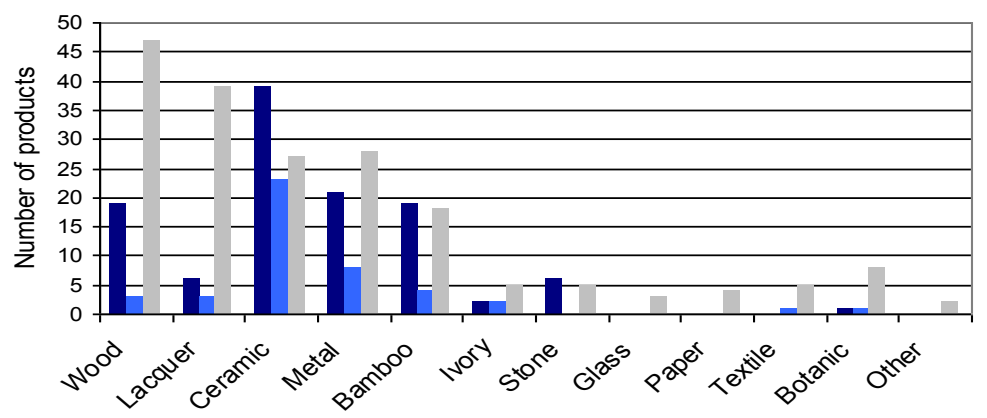

Eating ware Drinking ware Living ware

Fig. 2. Use of materials in Vietnamese traditional daily product groups in term of utility. 
At times, one product is made with two or more materials. Usually this is due to the required performance function of the product, but in many other cases, it is to satisfy esthetic preferences, and sometimes both demands are met. For the first reason, occasionally only a certain material is suitable for the task. However, whenever aesthetics are considered, the selection of materials, with a diversity of visual characteristics, shows up in product design. Table 1 presents the combination configuration of all types of materials in Vietnamese and Japanese traditional daily products.

Table 1. The available combination of materials in Vietnamese TDPs.

\begin{tabular}{|c|c|c|c|c|c|c|c|c|c|c|c|c|}
\hline & Bamboo & Botanic & Ceramic & Glass & Ivory & Lacquer & Feather & Metal & Paper & Stone & Textile & Wood \\
\hline Bamboo & & 0 & 0 & & & 0 & 0 & & 0 & & 0 & 0 \\
\hline Botanic & 0 & & & & & & & & & & & 0 \\
\hline Ceramic & 0 & & & & & 0 & & 0 & & & & 0 \\
\hline Glass & & & & & & & & 0 & & & & \\
\hline Ivory & & & & & & & & 0 & 0 & & & 0 \\
\hline Lacquer & 0 & & 0 & & & & & 0 & 0 & 0 & 0 & 0 \\
\hline Paper & 0 & & & & 0 & 0 & & & & & & \\
\hline Stone & & & & & & 0 & & & & & & 0 \\
\hline Textile & 0 & & & & & 0 & & & & & & 0 \\
\hline \multirow[t]{2}{*}{ wood } & 0 & 0 & 0 & & 0 & 0 & & 0 & & 0 & 0 & \\
\hline & 7 & 2 & 4 & 1 & 3 & 7 & 1 & 5 & 3 & 2 & 3 & 8 \\
\hline
\end{tabular}

The characteristics of the materials are defined according to the most general and fundamental properties that might affect the aesthetics of the products or the selection of materials: touch, reflection, surface, weight, opacity, source and availability. In each property, the scale was divided into three or four "most general" levels, shown in Table 2.

Table 2. Apparent characteristics of materials.

\begin{tabular}{|c|c|c|c|c|}
\hline Touch & Soft & Flexible & \multicolumn{2}{|l|}{ Hard } \\
\hline Reflection & Rough & Smooth & \multicolumn{2}{|c|}{ Shiny } \\
\hline Surface & Plain & Pattern & \multicolumn{2}{|c|}{ Texture } \\
\hline Weight & Light & Medium & \multicolumn{2}{|c|}{ Heavy } \\
\hline Opacity & Clear & Semi clear & Thin & Thick \\
\hline Availability & Mediocre & Available & \multicolumn{2}{|c|}{ Precious } \\
\hline
\end{tabular}

The results were then summarized into 6 diagrams representing the 6 properties of materials (Table 3). Radar diagrams indicate the orientation of combination.

From these diagrams, we can see that, in most cases, the black shapes seem to be very modest in turning to the direction of those combinations, almost avoiding the highest contrasting pair, for example, in the diagrams of properties: reflection, surface, and weight. This means that in Vietnamese traditional daily products the uniform is preferred in combining materials. For examples, hard materials used to be combined with other hard ones; materials with smooth and plain surface used to go with other smooth and plain ones. 
Table 3. The characteristics of the combination of materials in Vietnamese TDPs.

(n) Reflection

\subsection{Shapes \& forms characteristics}

Categories of the analysis were chosen from the most fundamental features of form that are supposed to cover all aspects of product's forms and be able to make clear the distinction between them at a certain level [15]. The features are: corner, line, volume, amount of elements, overall form, outline, unity of parts, function, and horizontal ratio. From those features, the more detail characteristics were determined to get clearer description of product's shape. Table 4 presents all 30 features' characteristics. 
Table 4. Shape feature's list and description.

\begin{tabular}{|c|c|c|}
\hline Feature & Description of feature & Characteristic of feature \\
\hline Corner & $\begin{array}{l}\text { Indicating corner types on the intersectional } \\
\text { edges of faces }\end{array}$ & $\begin{array}{l}\text { Sharp } \\
\text { Small arc } \\
\text { Large arc } \\
\text { Bevel } \\
\end{array}$ \\
\hline Line & Indicating line types on the surfaces of body & $\begin{array}{l}\text { Straight } \\
\text { Slight curve } \\
\text { Big curve } \\
\text { S-line } \\
\text { Twisty }\end{array}$ \\
\hline Volume & Indicating fatness of overall shape & $\begin{array}{l}\text { Fat } \\
\text { Medium } \\
\text { Slim }\end{array}$ \\
\hline $\begin{array}{l}\text { Amount of } \\
\text { elements }\end{array}$ & Indicating quantity of elements & $\begin{array}{l}\text { Abundant } \\
\text { Sufficient } \\
\text { Minimized }\end{array}$ \\
\hline Overall form & $\begin{array}{l}\text { Indicating the main form of product from general } \\
\text { view }\end{array}$ & $\begin{array}{l}\text { Geometric } \\
\text { Organic } \\
\text { Free form } \\
\text { Imitated }\end{array}$ \\
\hline Outline & $\begin{array}{l}\text { Indicating outline of the whole product shape } \\
\text { with details }\end{array}$ & $\begin{array}{l}\text { Sophisticate } \\
\text { Average } \\
\text { Simple }\end{array}$ \\
\hline Unity of parts & Indicating the correlation between forms of parts & $\begin{array}{l}\text { Uniform } \\
\text { Mix }\end{array}$ \\
\hline Function & Indicating functions the product shape offers & $\begin{array}{l}\text { Added function } \\
\text { Reduced function }\end{array}$ \\
\hline $\begin{array}{l}\text { Horizontal ratio } \\
\text { (Reference in } \\
\text { Table 6*) }\end{array}$ & $\begin{array}{l}\text { Indicating ratio between the narrowest and the } \\
\text { widest parts in the body of products }\end{array}$ & $\begin{array}{l}\text { High contrast }(\leq 1 / 4) \\
\text { Harmony }(1 / 2-1 / 3) \\
\text { Low contrast }(\geq 1 / 2) \\
\text { Equivalence }(\approx 1 / 1)\end{array}$ \\
\hline
\end{tabular}

The table 5 shows the parameters of 5 axes from Quantification Theory Type III analysis. And Figure $2 \& 3$ are graphs presenting result from this quantification analysis and cluster analysis.

Table 5. Parameters of analysis on Japanese samples.

\begin{tabular}{ccccc}
\hline $\begin{array}{c}\text { Axis } \\
\text { No. }\end{array}$ & $\begin{array}{c}\text { Eigen } \\
\text { value }\end{array}$ & $\begin{array}{c}\text { Percentage of } \\
\text { contribution }\end{array}$ & $\begin{array}{c}\text { Accumulation } \\
\text { contribution }\end{array}$ & $\begin{array}{c}\text { Coefficient } \\
\text { correlation }\end{array}$ \\
\hline 1 & 0.265 & $24.3 \%$ & $24.3 \%$ & 0.514 \\
2 & 0.199 & $18.3 \%$ & $42.6 \%$ & 0.446 \\
3 & 0.129 & $11.8 \%$ & $54.4 \%$ & 0.359 \\
4 & 0.117 & $10.8 \%$ & $65.2 \%$ & 0.342 \\
5 & 0.102 & $9.4 \%$ & $74.6 \%$ & 0.320 \\
\hline
\end{tabular}

From the distribution of categories in these graphs, meanings of the three main axes were read as following:

- Axis 1: Organic - Geometric (Form)

- Axis 2: Simple - Complex (Complexity)

- Axis 3: Bulbous - Delicate (Specification

From Figure $2 \& 3$, it is realized that Vietnamese shapes have a tendency toward Complex and Organic characteristics. 


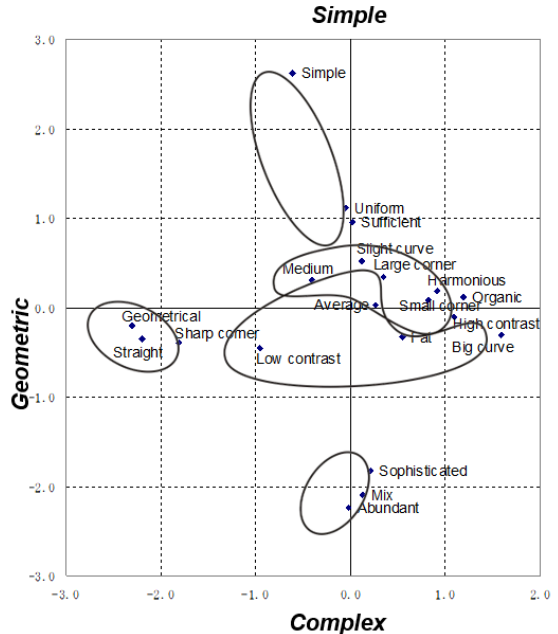

Fig. 2. Distribution of form's characteristics (axis 1 \& 2).

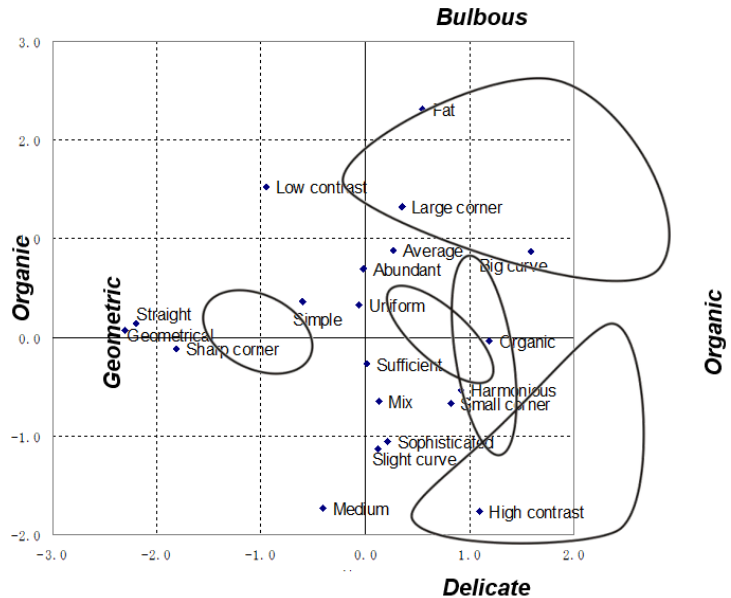

Fig. 3. Distribution of form's characteristics (axis $1 \& 3$ ).

In this part, the objective is to study more detail in the main ratios that strongly affect the attractive appearance of object's shape. In other word, this part of research went deeply into analyzing the gorgeousness or specification of products' outline. The category of this analysis is shown in Table 6.

By using Principle Component Analysis method, two components were extracted, which are named as General ratio (including Overall ratio) and Detail ratio (including Horizontal and Vertical ratios). Figure 4 is plots of samples' score from the analysis. If looking at area near H-Equivalence and V-Equivalence, the density of Vietnamese sample score distribution is very dilute, even some places are almost clear. This can be understood as the shapes with $\mathrm{V}$-Equivalence and H-Equivalence are not popular in Vietnamese products. As illustrated in the Figure 4, the shapes with V-Equivalence and H-Equivalence are likely to be geometrical.

Table 6. Category of ratio's analysis.

\begin{tabular}{|l|l|l|l|}
\hline & $\begin{array}{l}\text { Indicating ratio between the width of the } \\
\text { narrowest and widest parts of object's body }\end{array}$ \\
\hline $\begin{array}{l}\text { H - High contrast } \\
\mathrm{H} \text { - Low contrast } \\
\mathrm{H} \text { - Equivalence }\end{array}$ \\
\hline $\begin{array}{l}\text { Indicating ratio between the height of main parts } \\
\text { of object's body }\end{array}$
\end{tabular}




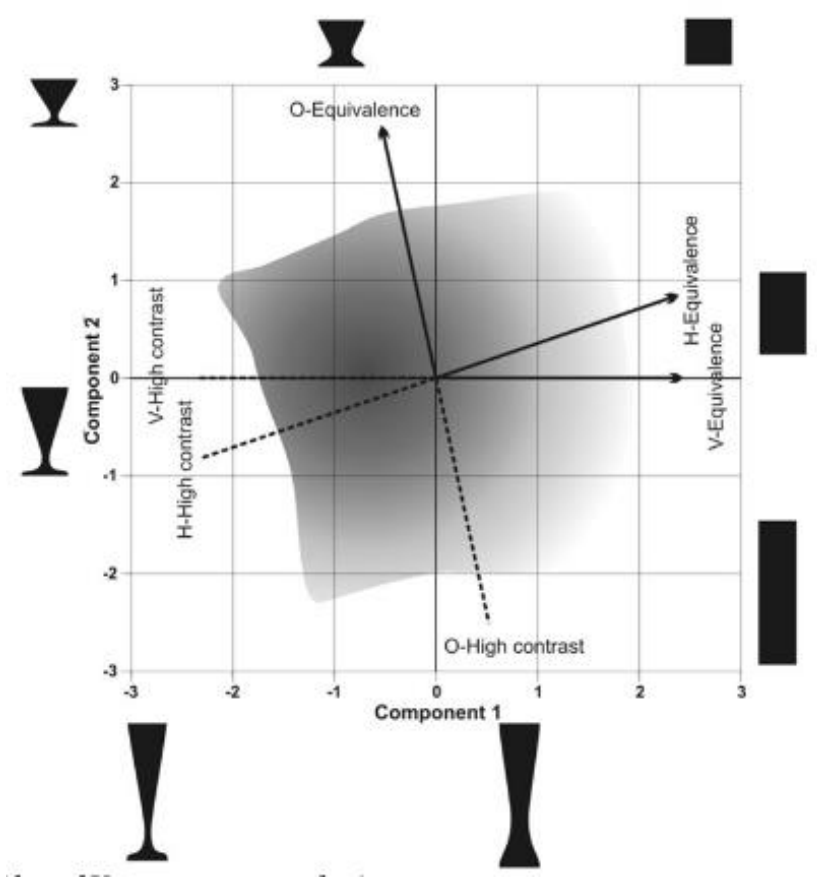

Fig. 4. Plot of Vietnamese samples' scores.

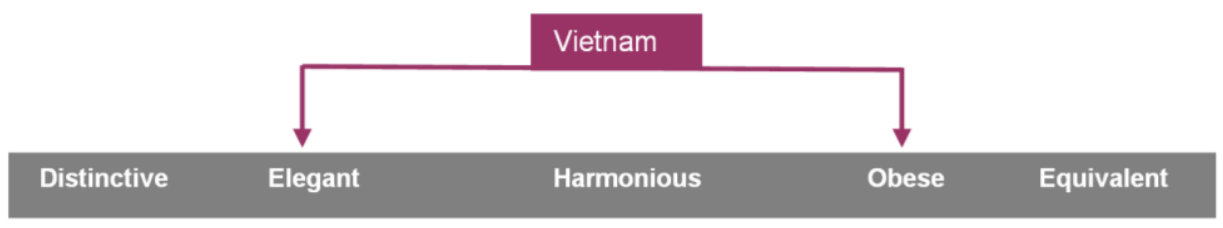

Fig. 5. Range of Vietnamese shapes in attractiveness scale.

According to the result shown in Fig.4, when dividing the attractiveness scale into five levels as shown in the graph below (Fig.5), the range of Vietnamese shapes is concentrated at the middle of the scale.

Last but not least, a result of the statistical analysis on Vietnamese imitated shapes in Fig. 6 shows that the percentage of products with a shape imitating animal is the highest. The share of dynamic subjects is $68 \%$, while the share of static ones is only $32 \%$. This can be explained by the fact that Vietnamese people believe in the existence of spirits or animism.

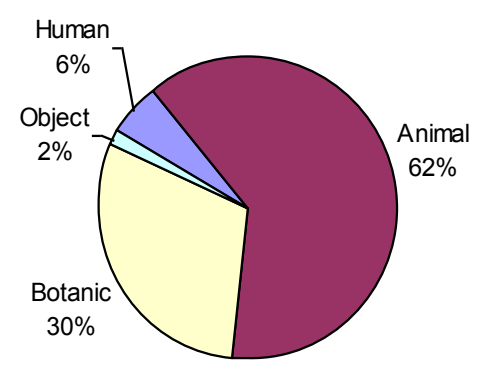

Fig. 6. Share of Vietnamese imitated shapes. 


\subsection{The use of colors}

This study aims to gain a general understanding of the use of colors. This use can be understood as the sequence of aesthetic opinions, appropriation, available manufacturing techniques, and surely, the effect from culture and beliefs.

The category included 35 colors for Vietnamese TDPs. Although in some books, more colors with tints and shades are listed, this research did not endeavor to make a detailed description about the colors themselves rather about overall use of them. Therefore, the most basic and essential colors were chosen, then divided into three groups (basic colors, secondary colors, and natural colors) as listed in the Table 7 below.

Table 7. Color categories.

\begin{tabular}{|c|c|c|c|c|c|c|c|c|c|c|c|c|c|c|c|c|c|c|c|c|}
\hline Group & \multicolumn{20}{|c|}{ Color categories } \\
\hline Basic colors & $\begin{array}{l}\frac{\breve{c}}{\tilde{m}} \\
\frac{\pi}{9}\end{array}$ & 总 & 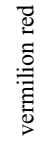 & 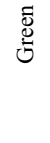 & $\frac{3}{0}$ & 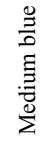 & & & & & & & & & & & & & & \\
\hline $\begin{array}{l}\text { Secondary } \\
\text { colors }\end{array}$ & 롱 & 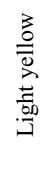 & बें & 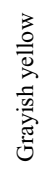 & $\begin{array}{l}5 \\
0 \\
0 \\
0 \\
0 \\
0 \\
0 \\
0\end{array}$ & 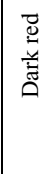 & $\begin{array}{l}\text { 善 } \\
\text { 音 }\end{array}$ & 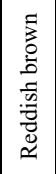 & 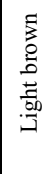 & 言 & 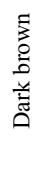 & 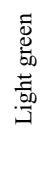 & 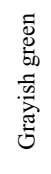 & 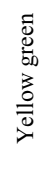 & 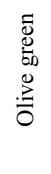 & 戸్ & 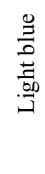 & 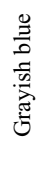 & $\begin{array}{l}\frac{0}{0} \\
0 \\
\frac{1}{\pi} \\
0 \\
0\end{array}$ & 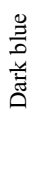 \\
\hline $\begin{array}{l}\text { Natural } \\
\text { colors }\end{array}$ & 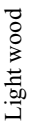 & 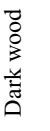 & ప్: & 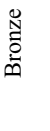 & $\stackrel{\bar{\nu}}{\stackrel{\vec{n}}{\bar{n}}}$ & 竞 & 部 & 总 & 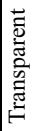 & & & & & & & & & & & \\
\hline
\end{tabular}

From Fig.7, we can see that the most frequently used colors in Vietnamese TDPs are in two groups (mostly cool and secondary colors) in descending order as follows:

- Group VN-I: Ivory, Cobalt blue, White.

- Group VN-II: Brown, Bronze, Dark brown, Light yellow, Green, Grayish yellow, Light green, Light brown.

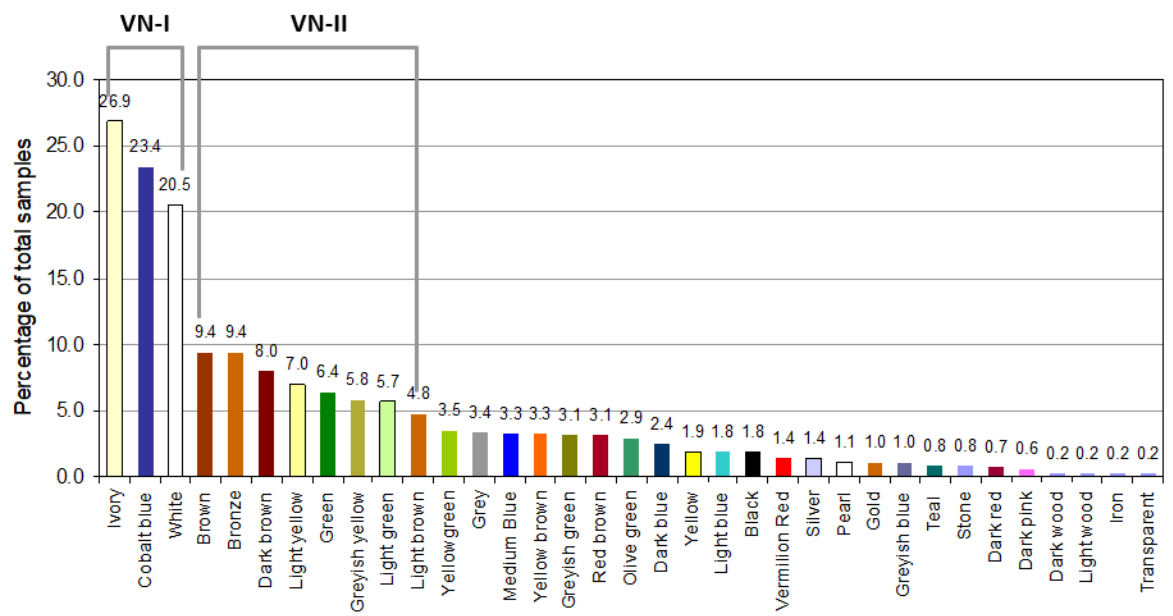

Fig. 7. Frequency of use of colors in Vietnamese TDPs. 
A further analysis was carried out to explore the use of colors according to their roles in coloring the products. Each color has its own voice according to its appearance but, more than that, is the role it plays as being part of a whole. In this study, roles were evaluated up to the three basic levels: base, main décor and secondary décor. These levels were determined by the covered area of each color on the surface of products. The base included colors covering over $60 \%$ of the surface of products, the main décor included those covering $20 \%$ $40 \%$, and the secondary décor included coverage of less than $20 \%$. However, in the case of a two-color combination, the color covering the smaller area was regarded as the main décor. Fig.8is the result of color's role statistic respectively from Japanese and Vietnamese samples.

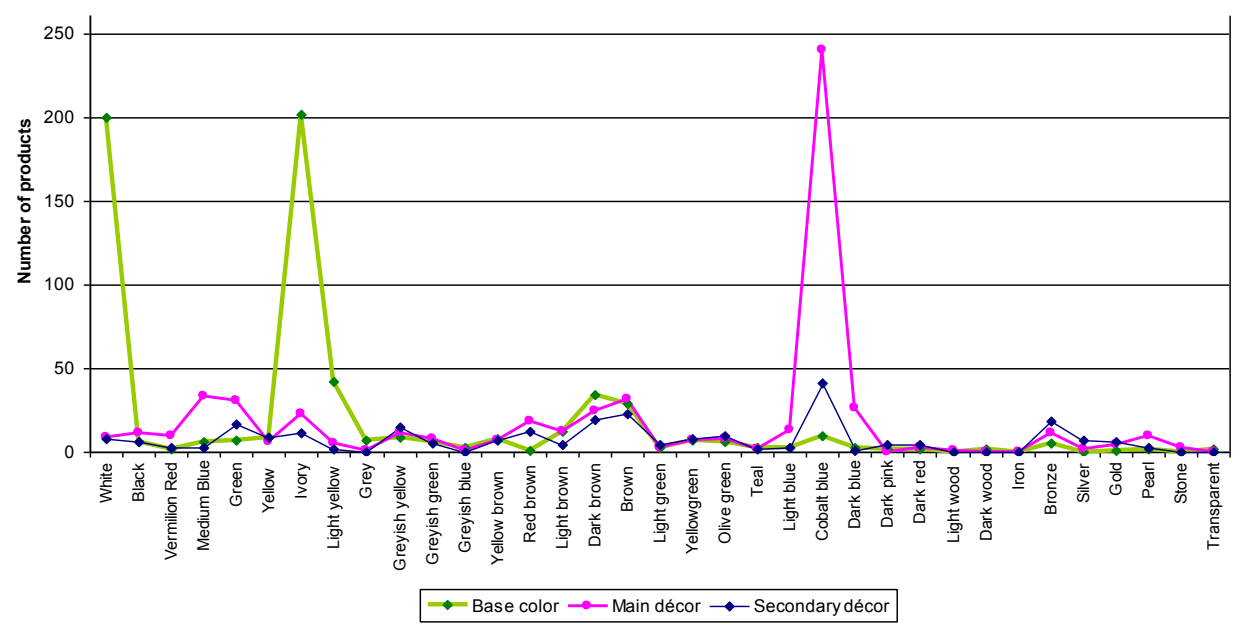

Fig. 8. Colors' role in Vietnamese TDPs.

The results show that, in Vietnamese TDPs, the most popular base colors were White, Ivory, Light yellow, Dark brown and Brown, in descending order; for the main décor it was Cobalt blue, Medium blue, Green, Brown, Dark brown, Dark blue; the secondary décor was Cobalt blue, Brown, Dark brown, Grayish yellow, Green and Bronze.It is quite clear that all of the light colors were intended mostly as a base, for instance, White, Ivory and Light yellow (as illustrated in Table 8). These light colors were rarely used as colors of decoration. Consequently the sole-color occurrencewas found often in light colors.

Table 8. The most popular base, main décor and secondary décor colors in Vietnamese TDPs.

\begin{tabular}{|c|c|c|c|c|c|c|}
\hline Base & $\stackrel{0}{3}$ & ì & 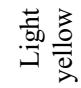 & 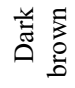 & 蒿 & \\
\hline $\begin{array}{l}\text { Main } \\
\text { décor }\end{array}$ & 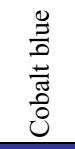 & 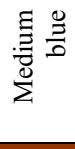 & 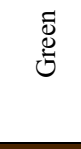 & 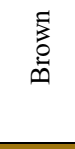 & 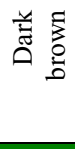 & 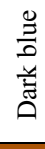 \\
\hline $\begin{array}{l}\text { Secondary } \\
\text { décor }\end{array}$ & 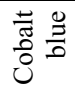 & 葛 & 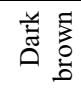 & 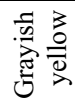 & 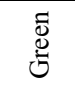 & $\begin{array}{l}\tilde{N} \\
\overline{0} \\
\text { D. }\end{array}$ \\
\hline
\end{tabular}


In a product, colors do not always functionalone. For contrast, they are appliedfor the purposes of creating a combination where each color makes an addition or improvement to the others. The methods for choosing and combining colors together are up to the aesthetic definition of craftsmen, tastes of people, and of course the availability of manufacturing techniques. The objective in the research is also to graspthe most essential sense in the way Vietnam people put colors together by analyzing available color combinations in TDPs.

From the survey, there are 6 types of combination in Vietnamese TDPs. The graph (Fig. 9) exposes that Vietnamese TDPs had a tendency of using a few colors in combinations, most commonly using just one, two or three colors.

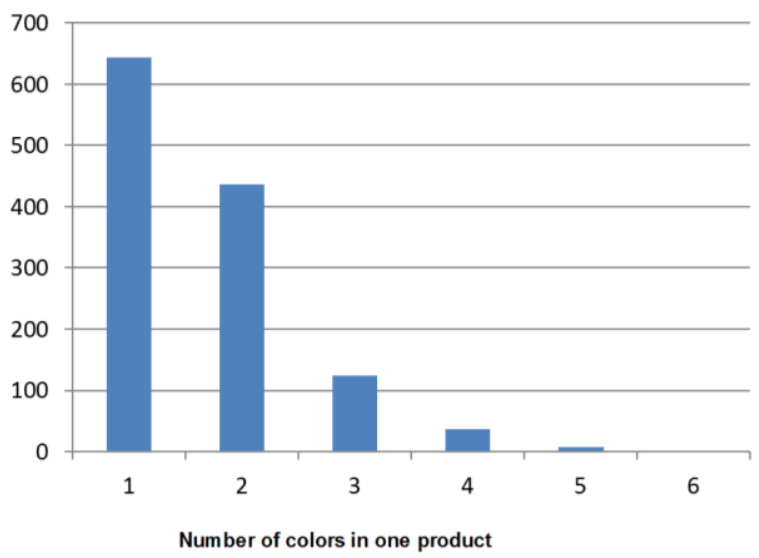

Fig. 9. Statistic result of the number of colors used in Vietnamese TDPs.

Continuing, more detailed characteristics of color combinations were investigated by directly analyzing each sample. In this research, one product was regarded as one color combination. The subjects of this study, shown in detail, are contrasts in Hue, Value, Chroma, and two Images of color - Cool \& Warm, Soft \& Hard. Each of these subjects is divided into three levels, which form 15 categories for the analysis. The number of colors in one combination, as is necessary, was also taken into the list of categories at this time. The total number of categories was then 18 as is shown in Table 9.

For a more visual understanding, the graph in Fig.10 was made by comparing, only extreme characteristics in each subject: Hue similar - Hue high contrast, Brightness equivalence - Brightness contrast, Subdued - Vivid, Cool - Warm and Soft - Hard. All data based on the recessive characteristics was converted into negative numbers for easier comparison. From the graph, in Vietnam TDPs, the special features are high contrast Value, subdued Chroma, cool and soft images. It is obvious that Vietnam has a tendency toward recessive characteristics in color combination.

Table 9. Categories of homogeneity and contrastin color combination.

\begin{tabular}{|c|c|c|c|c|c|c|c|c|c|c|c|c|c|c|c|c|c|c|}
\hline $\begin{array}{c}\text { Subjec } \\
t\end{array}$ & \multicolumn{3}{|c|}{$\begin{array}{c}\text { Number of } \\
\text { colors }\end{array}$} & \multicolumn{3}{|c|}{ Hue contrast } & \multicolumn{3}{|c|}{ Value contrast } & \multicolumn{3}{|c|}{ Chroma } & \multicolumn{3}{|c|}{$\begin{array}{l}\text { Cool-warm } \\
\text { Image }\end{array}$} & \multicolumn{3}{|c|}{$\begin{array}{c}\text { Soft-hard } \\
\text { Image }\end{array}$} \\
\hline $\begin{array}{c}\text { Value } \\
(*)\end{array}$ & $(-1)$ & (0) & $(+1)$ & $(-1)$ & (0) & $(+1)$ & $(-1)$ & (0) & $(+1)$ & $(-1)$ & $(0)$ & $(+1)$ & $(-1)$ & (0) & $(+1)$ & $(-1)$ & (0) & $(+1)$ \\
\hline 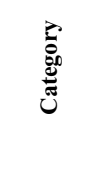 & $\begin{array}{l}\underset{3}{0} \\
0 \\
0 \\
0 \\
0 \\
0 \\
N \\
N\end{array}$ & 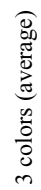 & 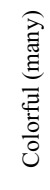 & 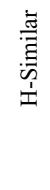 & 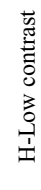 & 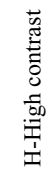 & 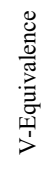 & 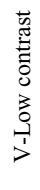 & 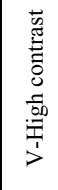 & 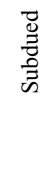 & $\sum_{0}^{\bullet 1}$ & $\stackrel{0}{3}$ & $\overline{8}$ & $\sum_{0}^{\infty}$ & 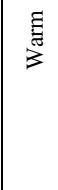 & 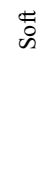 & $\begin{array}{l}\sum_{i=1}^{\star x} \\
\text { 壳 }\end{array}$ & تृّ̆ \\
\hline
\end{tabular}


$(*)$ : These values indicate the utmost of the contrast scale, which will subsequently be used for evaluating the combinations. Therein $(+1)$ presents dominant characteristics, $(-1)$ for recessive ones, and $(0)$ for mixed or neutral ones.

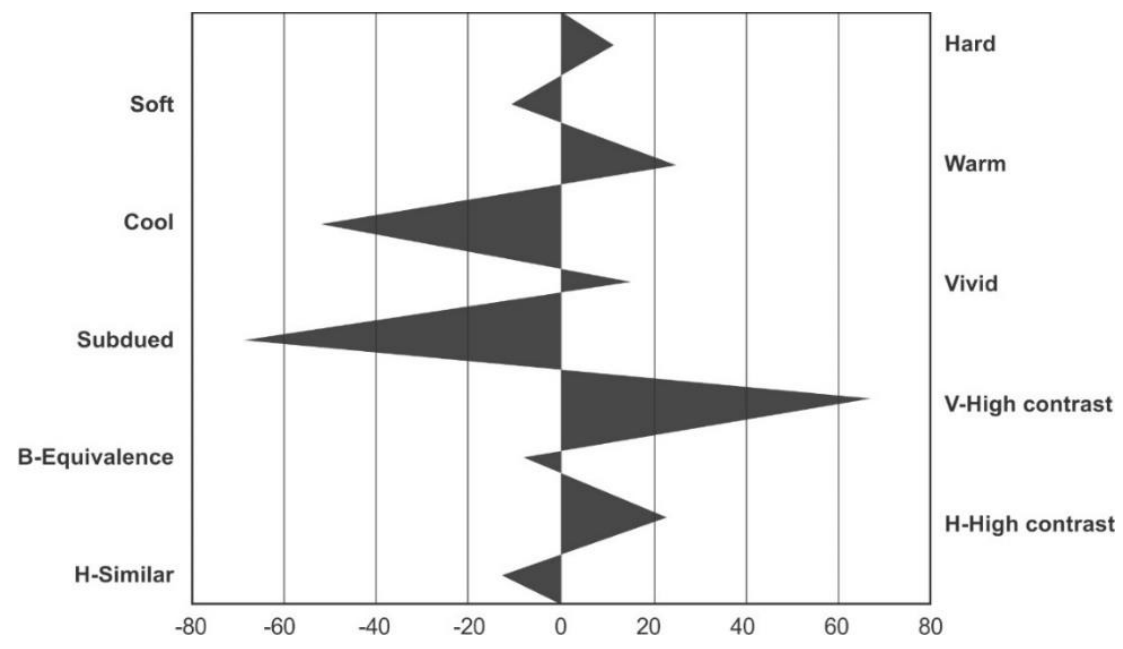

Fig. 10. Comparing homogeneity and contrast characteristics in Vietnamese color combination.

\subsection{Decoration's policy}

Decoration's manufacturing techniques are closely aligned with the utilization of materials. Fig. 11 shows the basic techniques of common types of materials used in Vietnam in past centuries.

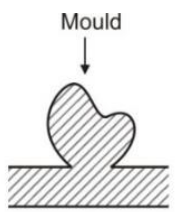

(1)

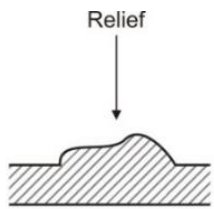

(2)

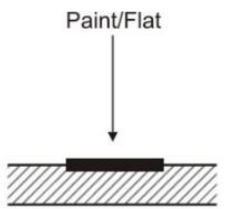

(3)

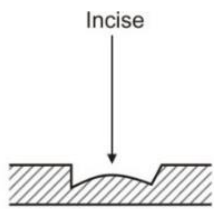

(4)

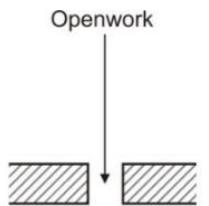

(5)

Fig. 11. Forms of decoration in Vietnamese TDPs.

The graph (Fig. 12) of the decoration's form reveals that, for Vietnam, the un-flat types (mould, relief, incised, openwork: 55\%) are used more frequently than the flat type. This means that, in Vietnamese TDPs, the form and shadow (which can be referred to as Yin and Yang) are likely to be the preferreddesigns in decoration.

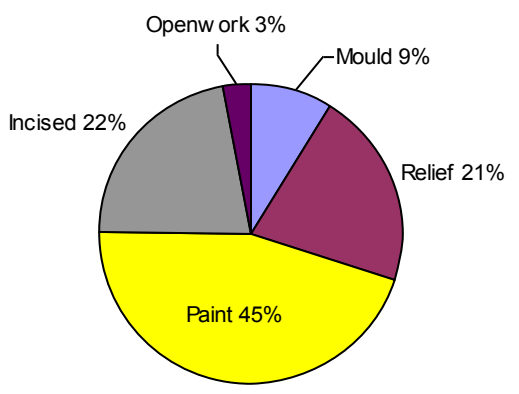

Fig. 12. Comparing forms of decoration in Japanese and Vietnamese TDPs. 
On the subject of the decorated area, Fig. 13 shows that Vietnamese craftsmen tended to cover $40-60 \%$ of product surface with decoration, a harmonious ratio.

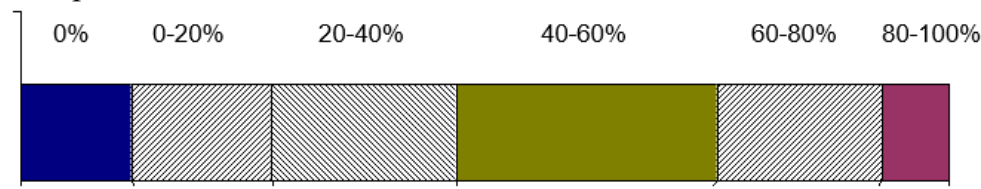

Fig. 13. Comparing decoration's covering area in Vietnamese TDPs.

Fig.14 is the comparison of types of patterns in Vietnamese TDPs' decoration. Through the graph, we can see that the most common pattern's types in Vietnamese TDPs are Stylized, Geometric pattern and the Mix.
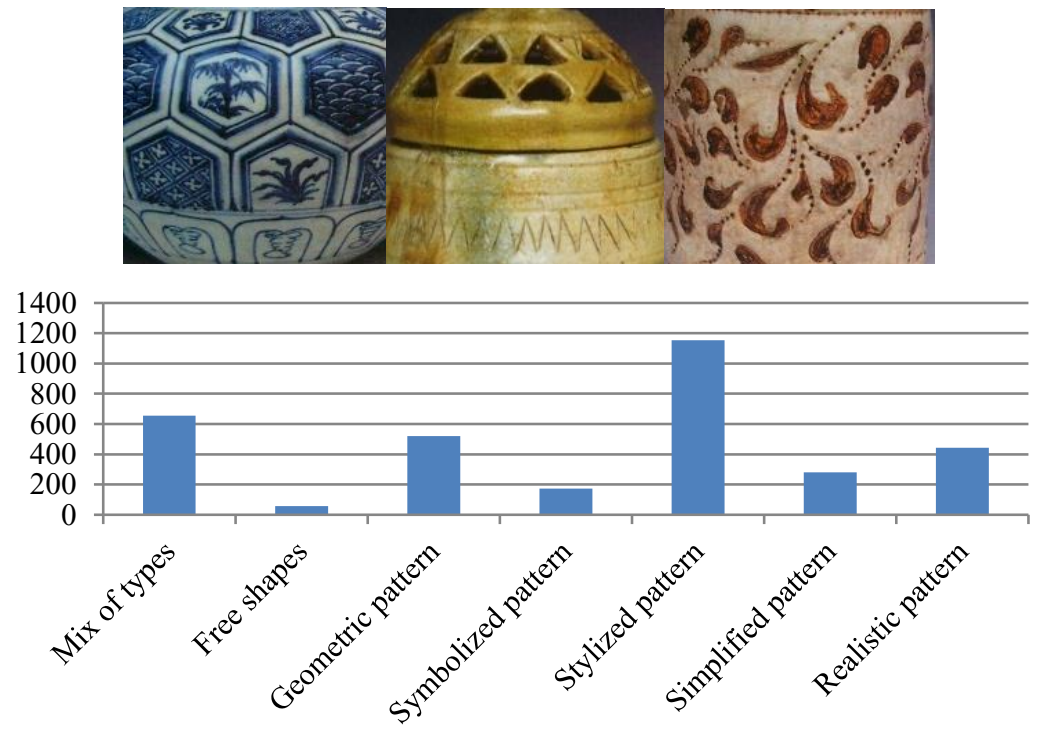

Fig. 14. Comparing types of patterns in Vietnamese TDPs.

\subsection{Synthesis}

In common object making process, form is the element which appears first, and is followed by decoration and color. The choice of decorative patterns and colors applied on an object shows the maker's sense of beauty and harmony. This investigation is attempts to extract the most basic and logical correlation between form and color in terms of design in TDPs.The method used for extracting relationship between form and color is Dual Scaling (done on Partition Table) and Cluster Analysis.

The research was concerned with the synthetic issue of colors rather than the specific colors themselves. The first issue is the quantity of colors in each product and in regards to there being a relationship between the colorfulness in one product and its form. The quantity of colors used in one product primarily controls the colorfulness of that product. In other words, the more colors that are used, the more colorful the product is.

The subjects used in this analysis were Quantity of colors, Shape, Volume, Outline and Horizontal ratio, which generated a total of 18 categories (Table 10). Therein, Shape, Volume, Outline and Horizontal ratio are re-examined subjects from the study on shape and form characteristics. 
Table 10. Categories of analysis on Quantity of colors and form.

\begin{tabular}{|c|c|c|c|c|c|c|c|c|c|c|c|c|c|c|c|c|c|c|}
\hline $\begin{array}{l}\text { Subj } \\
\text { ect }\end{array}$ & $\begin{array}{l}\text { Qua } \\
\text { colc }\end{array}$ & $\begin{array}{l}\text { ntity } \\
\text { rs }\end{array}$ & & & \multicolumn{4}{|c|}{ Shape } & \multicolumn{3}{|c|}{ Volume } & \multicolumn{3}{|c|}{ Outline } & \multicolumn{4}{|c|}{ Horizontal ratio } \\
\hline $\begin{array}{l}\text { Valu } \\
\text { e }\end{array}$ & 1 & 2 & 3 & 4 & 1 & 2 & 3 & 4 & 1 & 2 & 3 & 1 & 2 & 3 & 1 & 2 & 3 & 4 \\
\hline 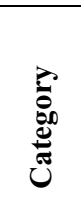 & $\begin{array}{l}\tilde{0} \\
\frac{0}{0} \\
\frac{0}{00} \\
\stackrel{\equiv}{0}\end{array}$ & $\begin{array}{l}\stackrel{\infty}{0} \\
\stackrel{0}{0} \\
\stackrel{\delta}{N}\end{array}$ & $\begin{array}{l}\text { ñ } \\
\frac{0}{8} \\
0 \\
m\end{array}$ & $\begin{array}{l}\bar{Z} \\
\frac{0}{0} \\
0\end{array}$ & 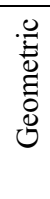 & 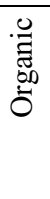 & 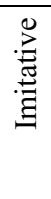 & 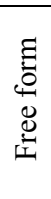 & $\stackrel{\Xi}{\tilde{n}}$ & $\begin{array}{l}\text { 声 } \\
\stackrel{\Xi}{\Sigma}\end{array}$ & त्ञ & $\begin{array}{l}\stackrel{0}{a} \\
\text { : }\end{array}$ & 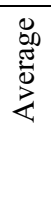 & 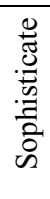 & 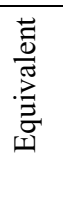 & $\begin{array}{l}\overrightarrow{\tilde{n}} \\
\mathbb{E} \\
\tilde{0} \\
0 \\
3 \\
0 \\
0\end{array}$ & 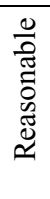 & 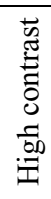 \\
\hline
\end{tabular}

The Cluster analysis on Vietnamese samples resulted in 3 clusters which are shown in Fig. 15 and clarified in Table 11. From Table 11, we can see, only Outline of shape have a relationship to Quantity of color. It is in a reverse tendency (examples in Fig. 16).

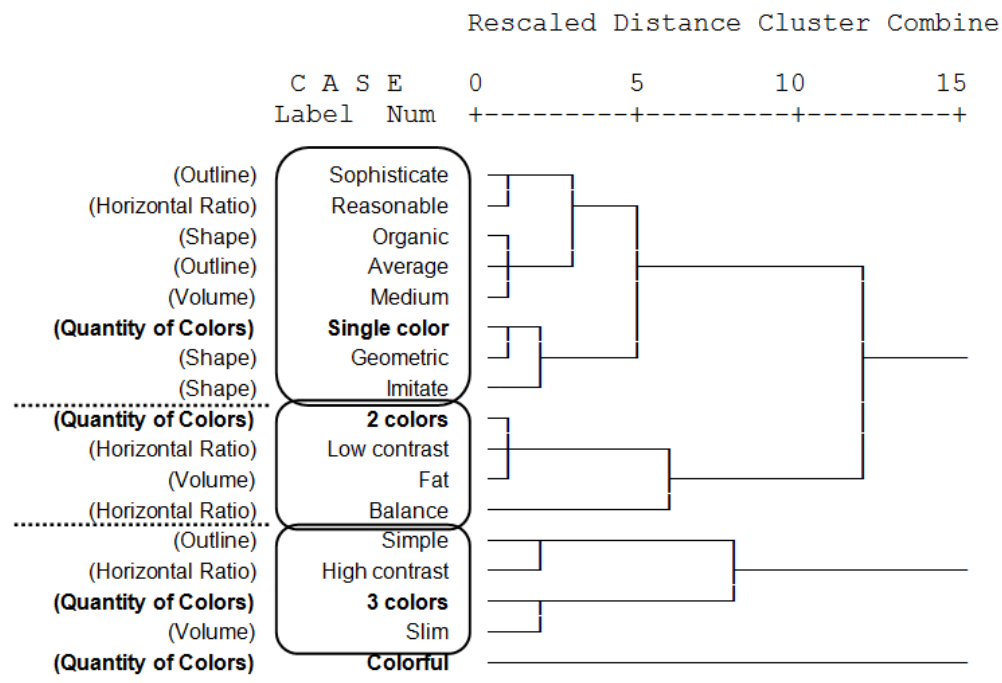

Fig. 15. Dendrogram of Cluster analysis on quantity of colors and form's characteristics in Vietnamese samples (Cumulative percentage contribution of 2 axes by dual scaling analysis: 0.841).

Table 11. Clusters of Quantity of colors and form characteristics inVietnamese samples.

\begin{tabular}{|c|l|c|c|c|c|}
\hline Cluster & $\begin{array}{l}\text { Quantity of } \\
\text { colors }\end{array}$ & Shape & Volume & Outline & Horizontal ratio \\
\hline 1 & $\begin{array}{l}\text { Single } \\
\text { color }\end{array}$ & $\begin{array}{c}\text { Geometric, } \\
\text { Organic, Imitative }\end{array}$ & Medium & $\begin{array}{c}\text { Sophisticate, } \\
\text { Average }\end{array}$ & Reasonable \\
\hline 2 & $\mathbf{2}$ colors & & Fat & & $\begin{array}{c}\text { Low contrast, } \\
\text { Equivalent }\end{array}$ \\
\hline 3 & $\mathbf{3}$ colors & & Slim & Simple & High contrast \\
\hline
\end{tabular}




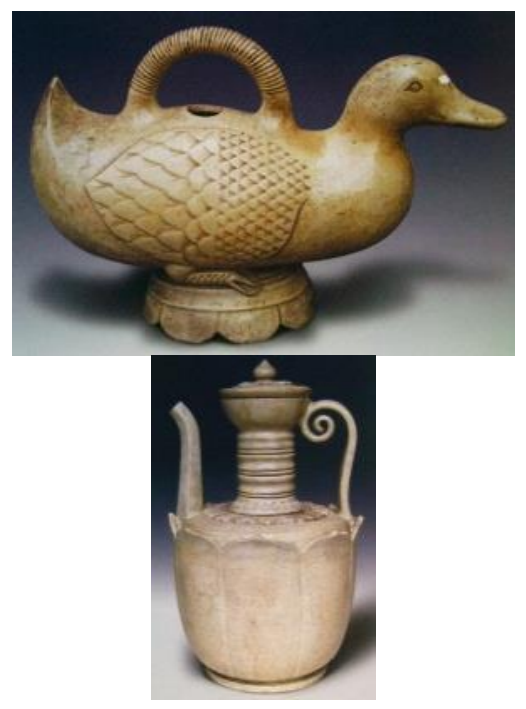

Single color - Sophisticate outline

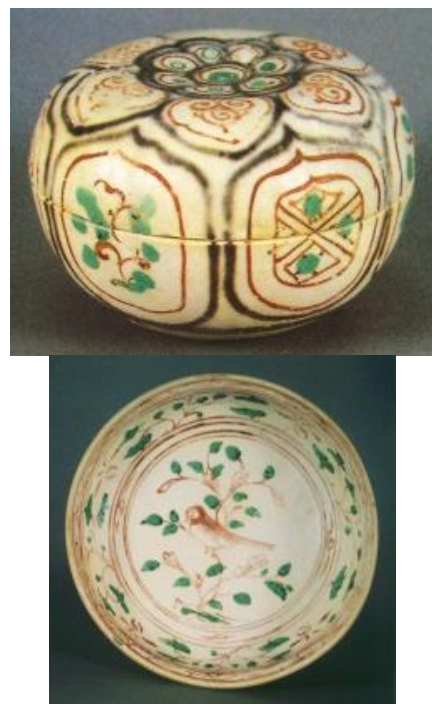

3 colors - Simple outline

Fig. 16. Examples for the correlation between Quantity of colors and Outline of form in Vietnamese TDPs.

Using the same method as above, the relationship between form's characteristics and other attributes of color such as Hue Contrast, Value Contrast, Chroma, Cool-Warm and SoftHard Image were explored in turn. Table 12 is the summary of results from investigations on the relationship between form and color characteristics. In the tables, $\boldsymbol{\Delta} \boldsymbol{\Delta}$ means a direct tendency, $\boldsymbol{\nabla} \boldsymbol{\Delta}$ means reverse tendency, and the empty cell means there is an unclear relationship.

Table 12. Summary of the correlations between form and color characteristics in Vietnamese TDPs.

\begin{tabular}{|l|c|l|c|c|}
\hline & Shape & Volume & Outline & $\begin{array}{c}\text { Horizontal } \\
\text { ratio }\end{array}$ \\
\hline Quantity of colors & & & $\boldsymbol{\nabla} \boldsymbol{\Delta}$ & \\
\hline Hue contrast & & & & \\
\hline Value contrast & & & $\boldsymbol{\nabla} \mathbf{\Delta}$ & \\
\hline Chroma & & & & \\
\hline Cool-warm image & & & & \\
\hline Soft-hard image & $\mathbf{\nabla} \mathbf{\Delta}$ & & $\boldsymbol{\Delta} \mathbf{\Delta}$ & $\mathbf{\nabla} \mathbf{\Delta}$ \\
\hline
\end{tabular}

Firstly, and in general, it is obvious that the relationship between color's and form's attributes in Vietnamese TDPs is not very tight. The most remarkable point is that Outline of form is always in an inverse proportion to brilliance of color (including Quantity of color and Value contrast). Supposing that form is created before a decision on colors is made, the complexity of form would determine how colorful the item would be. For example, sophisticated shape goes with low Value contrast and simple color combination, and vice versa. This can be understood as, in Vietnamese TDPs, in general, complexity of form usually tends to make a visual balance with brilliance of color. 
Finally, in order to examine the distinct balance between dominance and recession among the appearance's characteristics of Japanese and Vietnamese TDPs, a statistics is carried out through a digital database of all 4 of the appearance's components (material, form, color and decoration). The databases from earlier sections of research are used again, however, the digital value of all of the recessive characteristics are modified into -1, middle-scale characteristics are 0 , and dominant ones remain as 1 . For easy understanding, some examples of this transformed database are shown in Table 13.

Table 13. Example of digital values for analysis on the balance of dominance and recession.

\begin{tabular}{|c|c|c|c|c|c|c|c|c|c|c|c|c|c|}
\hline & \multicolumn{3}{|c|}{ Form } & \multicolumn{3}{|c|}{ Volume } & \multicolumn{3}{|c|}{ Outline } & \multicolumn{3}{|c|}{ Ratio } & \multirow[b]{2}{*}{ Sum } \\
\hline Sample & 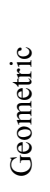 & 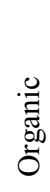 & 莺 & 离 & $\stackrel{\Xi}{\Xi}$ & $\stackrel{\Xi}{\varpi}$ & 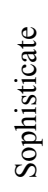 & 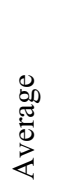 & $\begin{array}{l}\frac{0}{a} \\
\text { : }\end{array}$ & 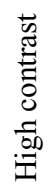 & 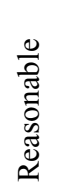 & 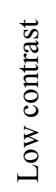 & \\
\hline VN 001 & & 0 & & 1 & & & & & -1 & & 0 & & 0 \\
\hline VN 002 & & 0 & & 1 & & & & & -1 & & & -1 & -1 \\
\hline VN 003 & -1 & & & & 0 & & & & -1 & & & -1 & -3 \\
\hline VN 004 & -1 & & & & 0 & & & & -1 & & 0 & & -2 \\
\hline VN 005 & & 0 & & & 0 & & & & -1 & & 0 & & -1 \\
\hline
\end{tabular}

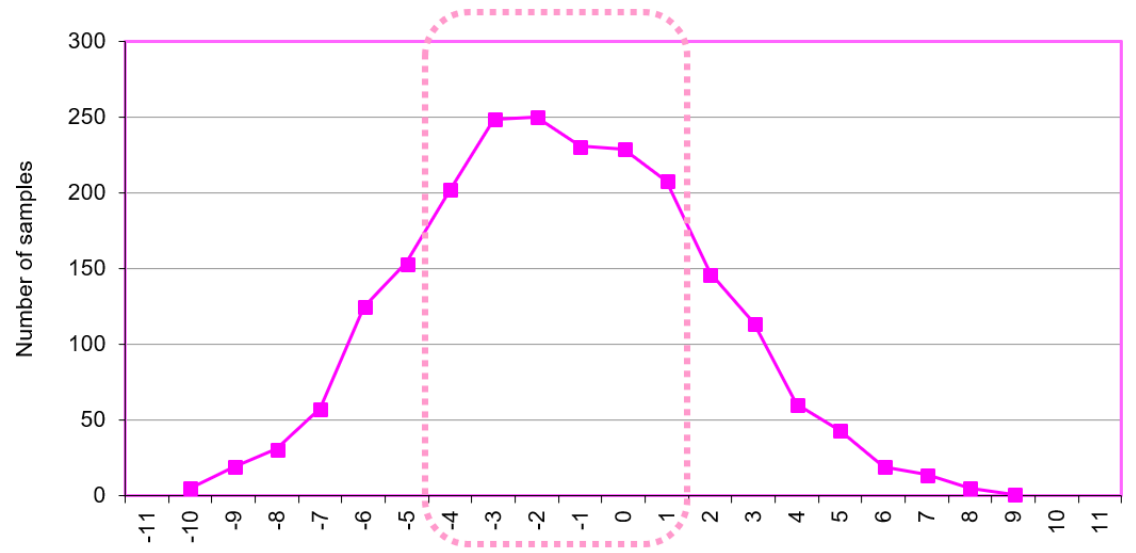

Fig. 17. Result of the sum of dominance and recession among appearance's characteristics of Vietnamese TDPs.

Finally, the sum of all those characteristics in each sample is calculated and compared to the others. The results are presented in Fig.17. The majority of samples have the sum of dominance and recession at the middle of the scale: Vietnam is from -4 to 1 . It is a balance but leaning toward recessive side. Or we can say that's not an absolute balance but a balance basing on recessive (Yin) bias. Yin-Yang is a theory explaining the composition of the universe and everything inside it. It is said that everything includes two parts: Yin (female/ recessive) and Yang (male/ dominant). The Yin-Yang philosophy, originating from Southern Asia culture seems to pervade deeply into Vietnamese culture: “...because of arising from South Asia culture, Yin-Yang philosophy has become an experienced foundation for shaping Vietnamese character afterwards" [16]. 


\section{Discussion}

\subsection{Understanding national design characters}

It is generally understood that material, form, color and decoration are regarded as four basic components of a product's appearances. In this study, all those components have in turn been addressed. Now, we will overlook those characteristics, rigor and relevance, in all sections, as a whole, in order to understand the relationship between them, a spirit or consciousness of beauty; because, although each of those components has a vital role in a product's appearance, the final beauty cannot be created by only one of those components, but from a mutual interaction of all of them as a whole.

For an easier review, all important results and conclusions on characteristics in material, form, color and decoration in Vietnamese TDPs are summarized. For simplification's sake, the most essential characteristics, which show strength and distinction of each appearance's component, are extracted and presented in Figure 18. After that, all are classified into clusters which recognize the repeat pattern of the overall characteristics of the four main appearance's components. Finally, the name of each cluster is listed as keywords. Those keywords are design characters for the country.

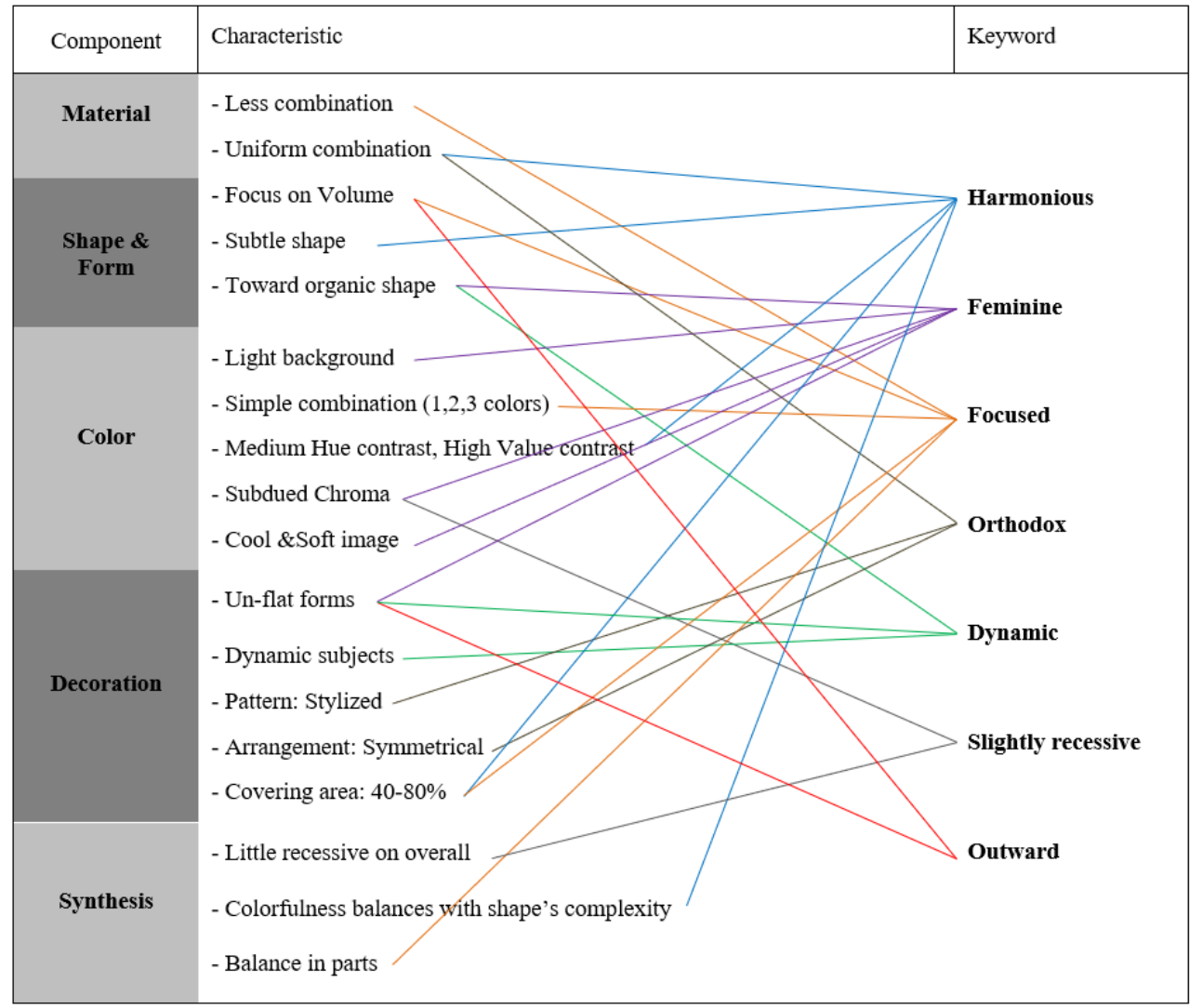

Fig. 18. Summary of remarkable characteristics of material, form, color and decoration in VietnameseTDPs. 


\subsection{Vietnamese urban outdoor products \& suggestion}

\subsubsection{Current issues}

Urban outdoor furniture or street furniture is a collective term for objects and pieces of equipment installed along streets for various purposes. It includes benches, bollards, post boxes, phone boxes, streetlamps, traffic lights, traffic signs, bus stops, bus shelter, public lavatories, watering troughs, and litterbin, etc. The design and placement of furniture takes into account aesthetics, visual identity, function, pedestrian mobility and road safety. According to Ministry of Construction (France) [17], a wide range of street furniture was classified by their function as in Table 14 .

Table 14. List of street furniture classified by their function.

\begin{tabular}{|l|l|l|}
\hline 1 & Decoration & $\begin{array}{l}\text { Gardening, planting, fountains, water views, and } \\
\text { sculptures }\end{array}$ \\
\hline 2 & Information & $\begin{array}{l}\text { City maps, clocks, poster plots, notice boards, newspaper } \\
\text { kiosks }\end{array}$ \\
\hline 3 & Protection and separation & Bollards \\
\hline 4 & $\begin{array}{l}\text { Recreation and hygiene } \\
\text { maintenance }\end{array}$ & $\begin{array}{l}\text { Benches, drinking fountains, trash containers, and public } \\
\text { toilets }\end{array}$ \\
\hline 5 & Parking & $\begin{array}{l}\text { Parking and charging facilities, parking separation } \\
\text { facilities }\end{array}$ \\
\hline 6 & Children play structure & Teeters, swings, and slides \\
\hline 7 & Technique & Lightings, signs, communications, and fire facilities \\
\hline 8 & Public transportation & Public transportation furniture and facilities \\
\hline 9 & Public communication & Mailboxes, postal and telephone booths \\
\hline
\end{tabular}

In Vietnam, the subject of urban outdoor furniture has not been put in attention yet. Up to now, there is no guideline for that, even in big cities like Hanoi and Ho Chi Minh. Only one sentence is found in the decree of Ministry of Construction, which mentionsgenerally that urban facilities such as street furniture, lights, and signage should secure the beauty, safety, convenience, consistency and harmony with the proportion of the architecture [18]. The range of common street furniture items is also very modest. Table 15 includes the list of all available items in Ho Chi Minh City with illustration.

There are still many problems in the design of those items in term of utility. However, as mentioned, the scope of this research is about the aesthetic aspect of the products. From the illustrations we can recognize a mixture of styles from European classic to international modern ones among Vietnamese urban outdoor furniture. There is no consistency between them all. Most of the shapes follow Western design or copy from oversea cities. We can selfdom see the identity of Vietnamese culture or local area here. 
Table 15. List of common street furniture items in Ho Chi Minh City center area

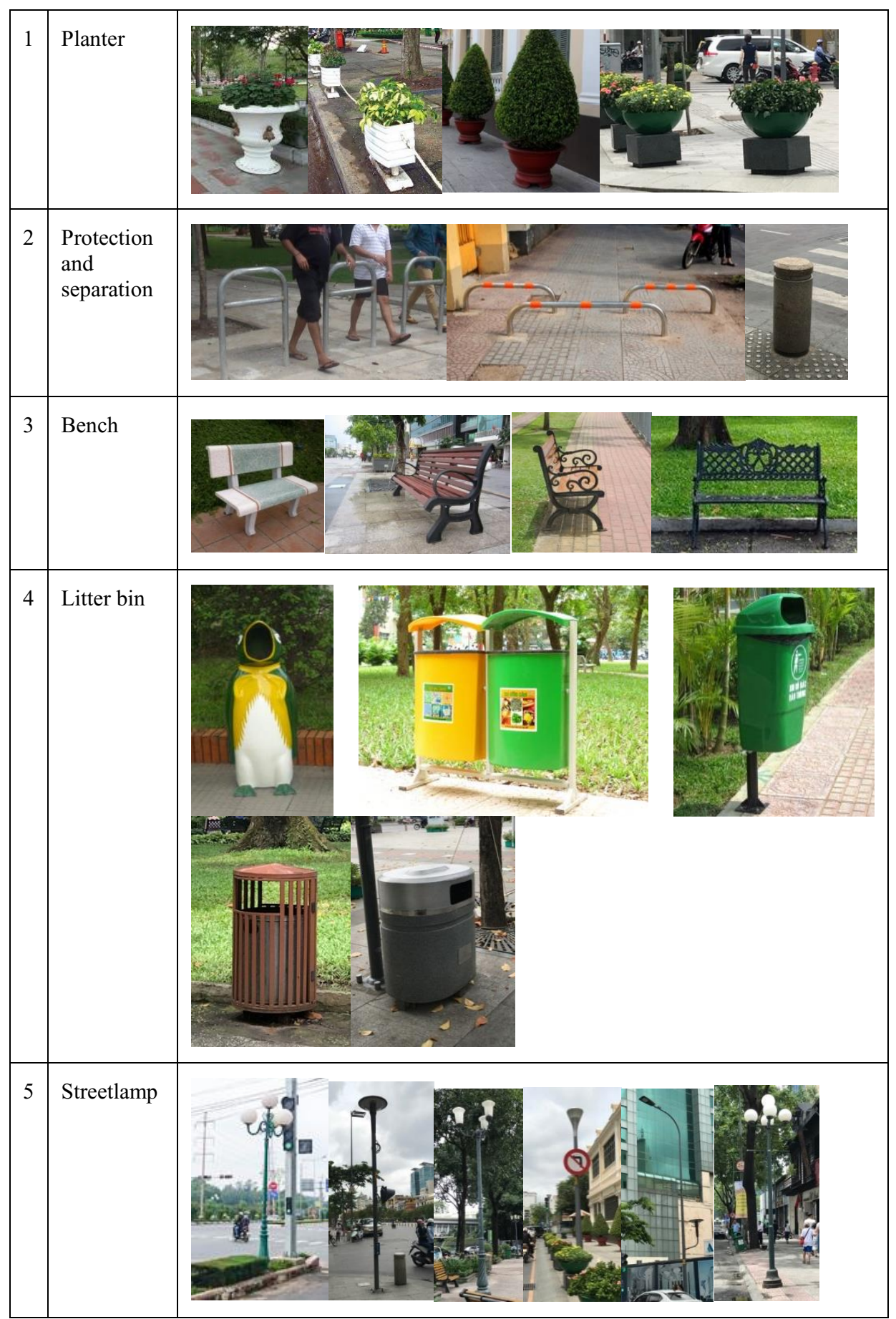




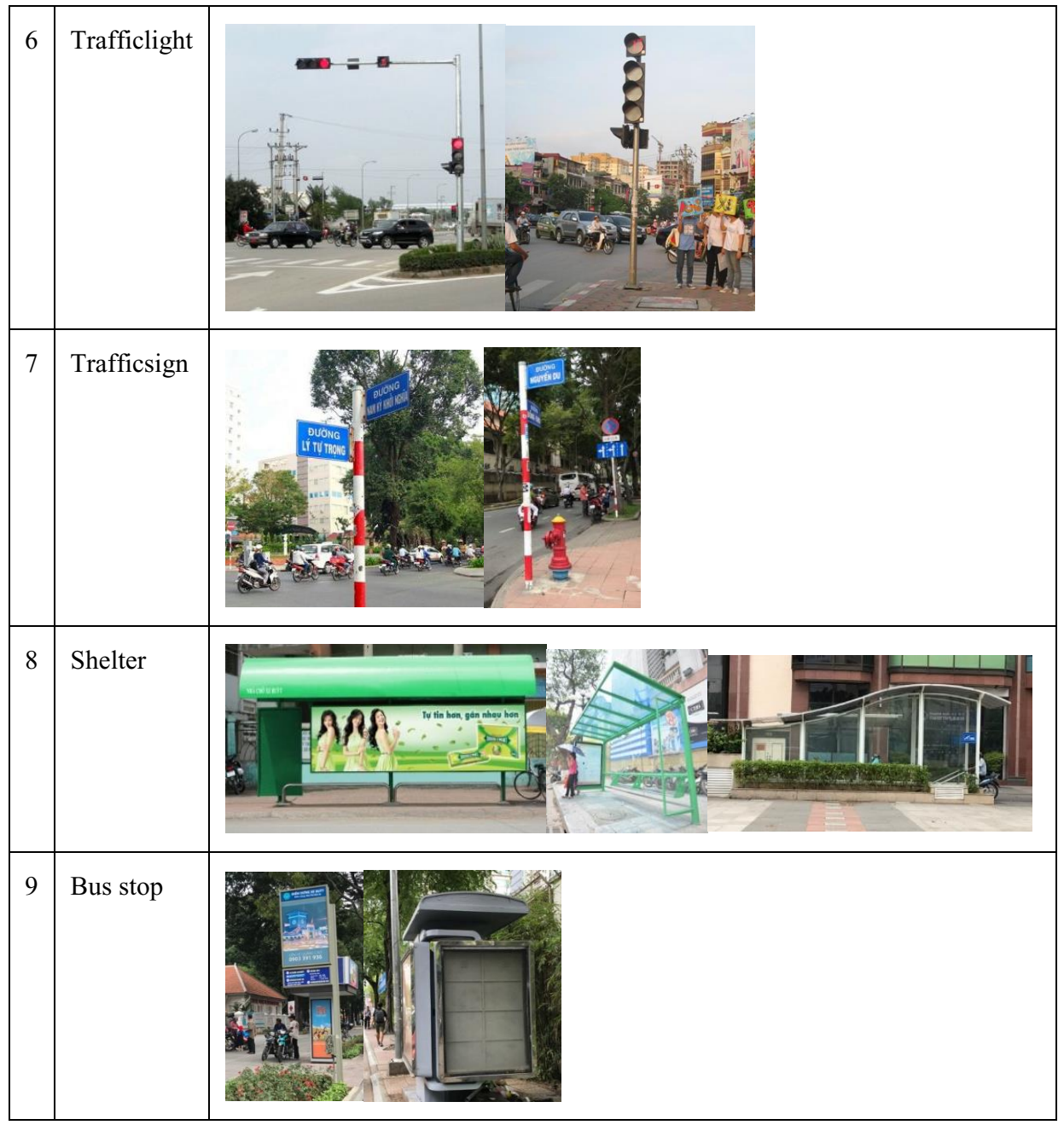

\subsubsection{Suggesting the guideline for aesthetic improvement}

Although comparatively small in scale, street furniture plays a significant role in streetscape. Along with other elements of urban design, it determines the quality of an urban environment and represents the image of a city. As it is one essential element of the urban environment that has close contact to humans and their activities, street furniture can easily get attention from people. Therefore, it can be an effective medium to introduce the culture of the local areas, especially the tourist cities like Hanoi, Hoi An, Hue and the big cities like Ho Chi Minh City attracting a large number of foreigners.

Due to their purpose of serving a variety of users, urban outdoor furniture are the products that has to be subjected to many issues such as safety, accessibility, utility, durability, weather resistance, installation, maintenance, etc.

Consequently, it is understood that their appearance are under a constraint whenever decisions of choosing materials, form, color and decoration are made. Besides, street furniture items are supposed to be placed throughout a city which usually has variety of architecture styles, both traditional and modern. Hence, if we try to create an identity by using rigid traditional style enforcement, we will fail to meet not only requirement of practicality 
but also the taste of new generation. Of course, there is another opportunity: creating a brand new identity. However that will result in unsustainable cultural development because there will be no continuity. This article suggests a sustainable solution for creating aesthetic identity of urban outdoor furniture by integrating only the essential characters of tradition into the modern designs. This method will let designers with flexibility to create the items that have traditional local identity appearance but still meet the requirement of all practical issues. From the characters of Vietnamese TDPs found out in previous sections of this study, Table 16 presents the guidelines for aesthetic improvement of Vietnamese urban outdoor furniture.

Table 16. Guidelines for aesthetic identity of Vietnamese products

\begin{tabular}{|c|l|}
\hline Component & Guideline \\
\hline \multirow{5}{*}{ Material } & $\begin{array}{l}\text { - Try to combining less materials in one product } \\
\text { - If a product should use several materials, then choose the ones with uniform } \\
\text { characteristics such as shiny with shiny, plain with plain, hard with hard, not too } \\
\text { much contrast. } \\
\text { - Ceramic, wood, bamboo and stone are recommended, but other materials such } \\
\text { as plastics and metal can also be the substitutes as long as the form, color and } \\
\text { decoration of the product still follow the guideline. }\end{array}$ \\
\hline \multirow{5}{*}{ Form } & $\begin{array}{l}\text { - Organic, symmetric and softS-line shapes with big curve are recommended, not } \\
\text { geometric ones with simple and clean outline, no sharp edge } \\
\text { - Subtle shape, not too much contrast in ratio, not slim } \\
\text { - All parts are uniform, not too many parts and elements }\end{array}$ \\
\hline \multirow{5}{*}{ Color } & $\begin{array}{l}\text { - Always use light background color } \\
\text { - Use simple combination (1,2,3 colors), not too many colors in one product } \\
\text { - Use the colors with medium Hue contrast, and high Value contrast together } \\
\text { - Most of colors should have subdued Chroma (secondary colors) } \\
\text { - Colors with cool \&soft image are recommended }\end{array}$ \\
\hline \multirow{5}{*}{ Ovecorall } & $\begin{array}{l}\text { - Un-flat forms (e.g. incise, relief, emboss and open-work) of decoration are } \\
\text { recommended } \\
\text { - Dynamic subjects (e.g. scroll, animal, plant, human figure, natural phenomena) } \\
\text { are recommended. Several subjects can be mixed together in one product. } \\
\text { - Stylized pattern are recommended, not realistic style } \\
\text { - Arrangement of the patterns should besymmetrical or centripetal } \\
\text { - Decoration should cover around 40-60\% of the whole body of the product }\end{array}$ \\
\begin{tabular}{|c|c|} 
- Harmonious and pleasant look, not too much brilliant or extravagant \\
- Colorfulness balances with shape's complexity: this mean, for example, if a \\
product has a complicate shape with un-even decoration such as relief, incise or \\
open-work, then it should be in plain color. \\
- Balance is reached in each components of the product's aesthetic appearance
\end{tabular} \\
\hline
\end{tabular}

\section{Conclusions}

It is generally understood that, over times, the definition of beauty and the tendency and movement of aesthetic styling has been changed continuously. In the modern development stage, now more than ever before, the product's standards is under many pressures from all fields such as economy, politics, environment, culture... and is affected by other movements such as globalization, modernization, economization, mobility...This fact has made the preference in contemporary product's aesthetics also changed dramatically comparing to the old time.

However, considering the importance of the conservation of a national design identity a part of cultural preservation, some historical essential beauty standards can be kept and 
continued in modern products. As in life, physical detail can be changed but the spirit is prolonged and conservative. Putting that spirit in the new form of physical detail, we can keep pace with modern development and meet new demands without losing our historical identity. In the context of this research, the spirit of national identity is inferred by the product's appearance characteristics. By the end of this research, the product's national design characters were implied in the keywords extracted from four components -material, form, color and decoration-of VietnameseTDPs. For the future product design, besides the common characteristics, it is necessary to bear in mind those traditional aesthetic appearance's characteristics to give product's appearance a distinction toward a sustainable cultural environment.

\section{References}

1. S. Naoto, Bulletin of Japanese Society for Science of Design 52(3), 21-30 (2005)

2. S. Naoto, Bulletin of Japanese Society for Science of Design 52(2), 51-60 (2005)

3. Y. Kentaro, Special issue ofbulletin of Japanese Society for Science of Design 8(2), 2431 (2001)

4. O. Katsuhiko, Special issue of bulletin of Japanese Society for Science of Design 8(2), 10-17 (2001)

5. H. Tosaku, Special issue of bulletin of Japanese Society for Science of Design 4(4), 2631 (1997)

6. I. Hiroshi, Journal of Tokyo Kasei Gakuin University 29, 95-117 (1989)

7. C. Campbell, Journal of Consumer Culture 5-1, 23-42 (2005)

8. J. Tumlin, Sustainable Transportation Planning (John Wiley \& Sons, Inc., Hoboken, New Jersey, 2012)

9. Urban design manual - part a: street and park furniture guidelines, Prepared by Urban Design, City - Strategy City of Ballarat, http://www.ballarat.vic.gov.au/media/1360202/street_and_park_furniture_guidelines.p df (2013)

10. Toronto's Coordinated Street Furniture Program Design and Policy Guidelines, Retrieved fromhttps://www1.toronto.ca/city_of_toronto/city_planning/urban_design/ files/pdf/vibrant_streets.pdf (2006)

11. P.H. Wan, Street furniture design principles and implementations, http://ira.lib.polyu.edu.hk/handle/10397/3628 (2008)

12. Z.L. Yu, Creation of urban environment: Landscape and environment facilities design (Tianjin University Press, 2003)

13. Co-ordinated Street furniture Urban Design Guideline, http://www.york.ca/wps/wcm/connect/yorkpublic/ecfd3aed-c3d9-40ce-afa1-

$9 \mathrm{caec} 4 \mathrm{a} 77 \mathrm{~b} 1 \mathrm{c} /$ YRT+Coordinated+Site+Furniture+Design+Guidelines.pdf?MOD=AJP ERES (2009)

14. N.T. Thu Trang, Bulletin of Japanese Society for Science of Design 56(3), 31-40 (2009)

15. N.T. Thu Trang, Bulletin of Japanese Society for Science of Design 56(3), 41-50 (2009)

16. Tran Ngoc, Add Discovering the identity of Vietnamese culture: typological-systematic views (Ho Chi Minh City publisher, 1996)

17. Les Amenagements Exterieur (Outdoor planning) (Ministry of Const., France, 1981)

18. URL :http://www.xaydung.gov.vn/web/guest/home/-/legal/2pBh/vi_VN/18/29833/37 